\title{
SIMPÓSIO INTERNACIONAL ANÁLISES FÍSICAS E QUÍMICAS NO ESTUDO DE MATERIAL ARQUEOLÓGICO
}

Durante os dias 29, 30 e 31 de maio de 1996, foi realizado na Sala da Congregação da Escola Politécnica da Universidade de São Paulo, o Simpósio Internacional sobre Análises Físicas e Químicas no Estudo de Material Arqueológico.

Promovido pelo Museu de Arqueologia e Etnologia e pelo Departamento de Engenharia de Minas da Escola Politécnica e com o apoio financeiro da FAPESP e da Área de Pós-Graduação em Arqueologia (FFLCH-USP), este simpósio teve como objetivo específico viabilizar o encontro - em uma única sede - de profissionais de áreas muito diferentes cujas especialidades podem contribuir para a melhor interpretação do documento arqueológico.

Como se sabe, uma das tendências da Arqueologia moderna, bem como da própria História, desenvolve-se na direção de conhecer o dia-a-dia das pessoas. Este esforço envolve o conhecimento das condições de vida e de moradia, das condições de higiene e saúde, das atividades e dos costumes diários, dos quais os inúmeros objetos de uso cotidiano são testemunhas loquazes. Assim, o conhecimento aprofundado dos materiais e dos processos de fabricação utilizados na produção de objetos metálicos e cerâmicos, ou daqueles usados para a pintura e para a construção civil constitui fator indispensável para a correta datação e interpretação dos mesmos.

As análises químicas, mineralógicas e físicas tornaram-se, portanto, uma ferramenta fundamental do estudo arqueológico. A análise mineralógica de uma terracota, por exemplo, permitirá estabelecer a temperatura de queima e assim definir o avanço tecnológico do povo que a fabricou em termos de construção de fornos. A mesma análise de um vidro ou de um esmalte fornecerá informações sobre o conhecimento dos pigmentos e de técnicas de concentração.

O grande problema é que arqueólogos e historiadores (como também geógrafos, sociólogos e antropólogos) têm uma formação exclusivamente humanista, que lhes veda o acesso a todo $o$ arsenal tecnológico e às informações decorrentes dele. Por sua vez, químicos, físicos, mineralogistas e engenheiros exibem o viés oposto, isto é, profundo conhecimento técnico e total ignorância humanística.
Este simpósio visou justamente reunir estes dois grupos aparentemente antagônicos em torno de uma mesma mesa, de modo que pudessem conhecer as necessidades recíprocas e trabalhar em conjunto.

Contamos, portanto, não apenas com a presença de arqueólogos clássicos, prehistoriadores brasileiros e profissionais da Arqueologia histórica brasileira, como também com físicos, químicos, engenheiros, biólogos e arqueometristas.

Em uma perspectiva mais ampla, a realização deste simpósio inseriu-se em uma preocupação permanente do Museu de Arqueologia e Etnologia com a formação de profissionais que estejam adequadamente preparados para o tratamento do patrimônio cultural como um todo. Com efeito, trata-se do terceiro encontro realizado pelo MAE/USP desde o princípio de 1995 com a finalidade de tratar de temas fundamentais para a formação de arqueólogos (simpósios sobre a Arqueologia do Sudeste brasileiro e sobre Teoria e Métodos em Arqueologia no 1o. e 2o. semestres de 1995 respectivamente).

A possibilidade de contar com a presença de especialistas de renome internacional permitiu um maior intercâmbio de conhecimentos e experiências bem como debates e questionamentos. $\mathrm{O}$ fato de poder contar com a tradução simultânea (do inglês para o português e do português para o inglês) atraiu o interesse de estudantes que compareceram maciçamente durante os três dias.

A programação do Simpósio constituiu-se de palestras, comunicações, entre outras atividades, assim distribuídas:

\section{9 de maio de 1996}

\section{Manhã}

Palestra de Abertura

"L'archéometrie en Europe: tendances actuelles et organisation". Prof. Dr. Tony Hackens (Univ. Católica de Louvain/ Conselho da Europa-PACT)

\section{Tarde}

Comunicações

"Adequação de matérias primas para uso industrial" Prof. Dr. Arthur Pinto Chaves. (Escola Politécnica -USP) 
"Aspectos Históricos da Indústria da mineração". Prof. Dr. Eduardo C. Damasceno (Escola Politécnica-USP).

"Técnicas metalúrgicas de elaboração de ligas e fundição". Engo. Luiz Eduardo de Arruda (SOFUNGE).

"Progresso na tecnologia do metal e inovações cerâmicas no mundo greco-romano". Profa. Dra. Maria Isabel D'Agostino Fleming (Museu de Arqueologia e Etnologia -USP).

"Estudos arqueométricos aplicados à análise de materiais de construção". Enga. Maria Thaís C. Affonso. (MaxPlanck-Institut für Kernphysik, Heidelberg).

\section{Visita à Exposição do MAE/USP}

30 de maio de 1996

\section{Manhã}

\section{Comunicações}

"Métodos e recursos de caracterização mineralógica e petrográfica". Dra. M.M.M.L.Tassinari (Escola Politécnica-USP), Dra. L.M. Sant'Agostino (Inst. Geociências-USP), Prof. Dr.Henrique Kahn (Escola Politécnica-USP).

"Análise mineralógica e determinação das origens da cerâmica orientalizante das Cíclades e da Grécia de Les$t e$ ". Profa.Dra. Haiganuch Sarian (FFLCH/ Museu de Arqueologia e Etnologia-USP)

\section{Palestra}

"Petrographical studies of archaeological ceramics". Prof. Andrew Middleton (Museu Britânico, Londres).

Tarde

\section{Comunicações}

"Environmental history of the Nordic-Baltic region: a valuable knowledge for cultural heritage interpretation" Profa. Dra. U. Miller (Universidade de Estocolmo/ Conselho da Europa-PACT).

"Métodos e recursos de análise química". Dra. Giuliana Ratti (Escola Politécnica-USP)

"Análise química de pigmentos de arte rupestre do $S E$ do Piaul". Profa. Dra. Maria Conceição Lage (Universidade Federal do Piauí-Teresina).

"Análise experimental da cerâmica popular de Conceição das Creoulas-Salgueiro, PE". Profa. Cláudia Alves (Universidade Federal de Pernambuco-Recife).

\section{Visita aos Laboratórios da Escola Politécnica}

31 de maio de 1996.

\section{Manhã}

\section{Comunicações}

"Métodos físicos no estudo de estatuetas de terracota gregas". Profa. Dra. Elaine Farias Veloso Hirata (Museu de Arqueologia e Etnologia-USP).

“ $O$ estudo de cerâmica arqueológica do Paraná por técnicas nucleares não destrutivas". Prof. Dr. Carlos Roberto Appoloni, P.S. Parreira, E. de Souza, R.M. da Cunha e Silva (Univ. Estadual de Londrina), Prof. Dr. J.C.A. Quacchia (IFUSP), Prof. Dr. V.F. do Nascimento Filho (ESALQ-USP), Prof. Dr. G.Gigante (Univ. Roma La Sapienza).
“Datação arqueológica por ressonância paramag nética eletrônica". Prof. Dr. Oswaldo Baffa Filho (Depto. de Física-FFCL, USP, Ribeirão Preto).

"A datação de material arqueológico pelas técnicas da termoluminescência, ressonância magnética eletrônica $e$ da luminescência oticamente estimulada". Prof. Dr Shigueo Watanabe (IFUSP).

\section{Tarde}

\section{Comunicações}

"O estudo da cerâmica pré-histórica no Brasil: das fontes de matéria prima ao emprego da microscopia petrográfica, difratometria de Raio X e microscopia eletrônica". Profa. Dra. Márcia Angelina Alves (Museu de Arqueologia e Etnologia-USP).

"Deteç̧ão de índices de temperatura da queima da cerâmica pré-histórica brasileira versus resistência cerâmica". Dr. Alexandre R. Zandonadi (Instituto de Pesquisas Tecnológicas - São Paulo).

"A microscopia óptica, a microscopia eletrônica de varredura, a difratometria de Raio $\mathrm{X}$ e a análise térmica no estudo da cerâmica pré-histórica brasileira". Dr. Evaristo Goulart (Instituto de Pesquisas Tecnológicas - São Paulo).

\section{Palestra de encerramento}

"Heavy elements' isotope ratios in archaeometry". Prof. Dr. S. Hölzl (Inst. Mineralogy and Petrography-Universidade de Munique).

As palestras oferecidas durante o Simpósio foram complementadas com visitas à Exposição de longa duração do MAE/USP - Formas de Humanidade - e aos Laboratórios do Departamento de Engenharia de Minas da Escola Politécnica. Para os alunos de Arqueologia, esta última visita foi de grande interesse pois permitiu a eles compreender, na prática, a importância da aplicação de uma metodologia específica para a melhor interpretação do documento arqueológico.

$\mathrm{Na}$ organização do Simpósio merece destaque a contribuição do Grupo PACT da Comunidade Européia. Graças a ela pudemos contar com a palestra da Profa. Dra. Urve Miller da Universidade de Estocolmo que tratou da paleoecologia, abrindo mais um campo de abordagem técnica do material arqueológico. Por outro lado, o Prof. Tony Hackens - vice-presidente do Grupo - trouxe pessoalmente, como doação à Biblioteca do MAE, vinte e dois volumes da Revista PACT Journal for Physical, Chemical, Biological and Mathematical methods applied to Archaeology, que estão hoje à disposição de profissionais e alunos.

Como conclusão, gostaria de salientar a importância que o Simpósio teve do ponto de vista cien- 
tífico, principalmente para os arqueólogos e para os estagiários e alunos do MAE/USP. Novas perspectivas foram abertas para a interpretação de material arqueológico, novos caminhos e possibilidades foram apresentados de maneira precisa e concreta.

Dentre estas perspectivas de pesquisa conjunta, viabilizadas pelo Simpósio, merecem destaque em primeiro lugar as tratativas iniciadas para a for- mação de um laboratório - sediado na USP - de análises físicas e químicas aplicadas ao estudo de material arqueológico e, em segundo lugar, a comunicação permanente - via internet - entre os especialistas interessados na aplicação de análises físicas, químicas, biológicas ao estudo do patrimônio ou herança cultural dos diversos países graças às inscrições feitas pelo Prof. Tony Hackens durante o Simpósio.

Maria Beatriz Borba Florenzano*

Recebido para publicação em 12 de dezembro de 1997.

(*) Museu de Arqueologia e Etnologia da Universidade de São Paulo, organizadora do Simpósio, juntamente com o Prof. Dr. Arthur Pinto Chaves, da Escola Politécnica/USP. 